\title{
TOLERÂNCIA DE CULTIVARES DE ARROZ EM ESTÁDIO DE PLÂNTULA A DIFERENTES NÍVEIS DE FERRO EM SOLUÇÃO NUTRITIVA ${ }^{(1,}$
}

\author{
CARLOS EDUARDO DE OLIVEIRA CAMARGO (2), Secão de Arroz e Cereais de Inverno, \\ Instituto Ayronômico.
}

\section{RESUMO}

Foram estudados sete cultivares de arroz em soluções nutritivas, sem arejamento, contendo quatro níveis de ferro $(0.56 ; 100$; 200 e $400 \mathrm{mg} /$ /itro), mantendo-se constante a temperatura das soluções de $30 \pm 1^{\circ} \mathrm{C}$, e o pH, 4,0. A tolerância foì medida pelo comprimento médio da raiz primária e pelo peso seco total da parte aérea de vinte plântulas cultivadas durante dez dias em soluções nutritivas contendo diferentes concentrações de ferro. A presença das; doses elevadas de ferro $(100,200$ e $400 \mathrm{mg} /$ litro $)$ foi prejudicial a todos os cultivares estudados, os quais mostraram sintomas tipicos de toxicidade de ferro, dependendo em intensidade do grau de tclerância de cada um. Os teores de ferro ( $\mathrm{ppm}$ ) aumentaram na parte aérea de todos os cultivares, em função do aumento das concentraçōes de ferro nas soluções nutritivas. A maior tolerância do Pérola pareceu ser devida a uma menor absorção de ferro das soluções em comparação com os outros cultivares estudados. A presença de altos teores de ferro na parte aérea dos cultivares, com reaçōes intermediárias e sensiveis a doses crescentes desse elemento nas soluções, indicou que suas respostas seriam devidas a uma maior ou menor tolerância às altas concentrações de ferro no interior das folhas, e não a uma maior ou menor absorção desse elemento das soluções.

\section{INTRODUÇÃO}

A toxicidade de ferro é uma desordem nutricional do arroz irrigado associada com excesso de ferro solúvel na água (10). E caracterizada

(1) Recebido para publicação a 13 de setembro de 1982.

(2) Com bolsa de suplementação do CNPq. 
pela descoloração das folhas, com exceção da nervura central, as quais tornam-se de cor púrpura, vermelho-acastanhada, laranja ou amarela, e mais tarde secam, mostrando uma aparência de queimadura nas plantas. As raízes são escassas, ásperas e de coloração castanho-escura. Esses sintomas ocorrem em solos ácidos, freqüentemente em associação com salinidade, deficiência de fósforo e baixa concentraçăc de bases ( 8 , 9, 11, 12).

Sintomas similares àqueles da toxicidade de ferro foram observados em regiōes produtoras de arroz no Estado de Santa Catarina, onde as folhas afetadas por ocasião da maturação apresentavam teores de ferro superiores a $846 \mathrm{ppm}(\boldsymbol{7})$.

Foi observado que os sintomas de toxicidade de ferro não ocorreram em solos na presença de uma das seguintes situaçōes: boa drenagem, submersão do solo retardada, alta concentração inicial de nitrato, ou quando foi adicionado nitrato de sódio para retardar o processo da redução (11). Por outro lado, os resultados indicaram que os distúrbios associados à toxicidade de ferro foram encontrados somente em arroz irrigado, estavam relacionados com drenagem deficiente e ocorriam quando os campos foram indevidamente mantidos sob água antes do plantio (11).

Cultivares de arroz com tolerância genética à toxicidade de ferro são considerados úteis em muitas várzeas na Libéria (13) onde sintomas de toxicidade se desenvolvem na maioria das culturas de arroz. Nessas condições, o cultivar IR-5 teve sua produção reduzida em $40 \%$. Através do melhoramento genético, foi selecionado o cultivar Suakoko-8, que produziu $20 \%$ a mais que o 'IR-5' em condições de toxicidade de ferro.

Muitos trabalhos realizados em condiçōes de solo diferenciaram cultivares de arroz tolerantes, moderadamente tolerantes e sensíveis à toxicidade de ferro $(\mathbf{2 , 3 , 4 , 5})$. Entre os tolerantes, destacaram-se: IR-1552, IR-20, IR-36, IR-42, IR-43, IR-44, Mat Candu e Pokkali, e, entre os sensiveis: IR-5, IR-8, IR-759-79-2, ICA-10, Monolaya e Purbachi.

Considerando as possíveis interaçōes existentes nos solos ácidos entre ferro e os demais elementos, o presente trabalho tem por objetivo estudar o comportamento de cultivares de arroz em estádio de plântula, em solução nutritiva, sem arejamento, contendo diferentes concentrações de ferro. Foi escolhida a fase de plântula para a avaliação de fontes de tolerância, objetivando, no futuro, a separação de plântulas tolerantes de populações segregantes provenientes do programa de melhoramento genético do arroz do Instituto Agronômico, as quais poderiam ser transplantadas para condições de vasos ou de campo, onde seleçōes para outros caracteres agronômicos seriam executadas.

\section{MATERIAL E MÉTODOS}

O experimento foi realizado em parcelas subdivididas, dispostas em blocos ao acaso, com duas repetições, onde as parcelas foram compostas 
por quatro concentraçōes de ferro $(0,56 ; 100 ; 200$ e $400 \mathrm{mg}$ /litro) e, as subparcelas, por vinte plântulas de sete cultivares de arroz. A concentração de $0,56 \mathrm{mg} /$ litro de ferro foi utilizada em virtude de trabalhos por MOORE et alii (8), que a empregaram nas soluçōes nutritivas completas. As concentrações de 100, 200 e $400 \mathrm{mg} /$ litro de Fe foram escolhidas, levando-se em consideração os trabalhos desenvolvidos por TANAKA \& YOSHIDA (12), que mostraram que durante o desenvolvimento da planta de arroz (perfilhação), $70 \mathrm{ppm}$ de Fe nas folhas seria 0 índice de deficiência e $300 \mathrm{ppm}$ de $\mathrm{Fe} \mathrm{o}$ indice de toxicidade.

Os cultivares estudados foram os seguintes: Blue Bonnet, Pérola, IAC-120, IAC-435, IAC-899, IR-8 e IR-841, os quais são plantados em condições de irrigação.

Em cada uma das repetiçōes, aproximadamente $20 \mathrm{~g}$ de sementes dos sete cultivares de arroz foram cuidadosamente lavados com uma solução de hipoclorito de sódio a $10 \%$ e colocados para germinar em caixas de Petri por 48 horas, quando iniciaram a emergência.

Foram escolhidas visualmente oitenta sementes uniformes e germinadas de cada cultivar e colocadas eqüitativamente sobre o topo de quatro telas de náilon, que foram adaptadas sobre quatro vasilhas plásticas com capacidade de 8,3 litros, contendo solução nutritiva completa. Desse modo, as sementes foram mantidas úmidas e as radículas emergentes, tocando na solução, tinham um imediato suprimento de nutrientes.

A composição da solução nutritiva completa, preconizada por MOORE et alii (6) foi a seguinte: $\mathrm{Ca}\left(\mathrm{NO}_{3}\right)_{2} 4 \mathrm{mM}$; $\mathrm{MgSO}_{4} 2 \mathrm{mM} ; \mathrm{KNO}_{3}$ $4 \mathrm{mM} ;\left(\mathrm{NH}_{4}\right)_{2} \mathrm{SO}_{4} 0,435 \mathrm{mM} ; \mathrm{KH}_{2} \mathrm{PO}_{4} 0,5 \mathrm{mM} ; \mathrm{MnSO}_{4} 2,0 \mu \mathrm{M} ; \mathrm{CuSO}_{4}$ $0,3 \mu \mathrm{M} ; \mathrm{ZnSO}_{*} 0,8 \mu \mathrm{M} ; \mathrm{NaCl} 30 \mu \mathrm{M} ; \mathrm{Fe}-\mathrm{CYDTA} 10 \mu \mathrm{M} ; \mathrm{Na}_{2} \mathrm{MoO}_{4} 0,1 \mu \mathrm{M}$ e $\mathrm{H}_{3} \mathrm{BO}_{3} \quad 10 \mu \mathrm{M}$. $\mathrm{O}$ pH da solução foi ajustado para 4,0, com uma solução de $\mathrm{H}_{2} \mathrm{SO}_{ \pm} 1 \mathrm{~N}$. As vasilhas contendo a solução furam colocadas em banho-maria a $30 \pm 1^{\circ} \mathrm{C}$ no interior do laboratório, sendo o experimento mantido com luz fluorescente durante toda a sua duração.

As plântulas desenvolveram-se nessas condições por 48 horas. Após esse período, as quatro telas de náilon contendo cada uma vinte plântulas dos sete cultivares foi transferida para quatro vasilhas plásticas contendo, nas suas soluções tratamentos, respectivamente, 0,$56 ; 100 ; 200$ e $400 \mathrm{mg} /$ litro de ferro na forma $\mathrm{FeSO}_{4} 7 \mathrm{H}_{2} \mathrm{O}$. Com exceção desse elemento, a composição da solução tratamento foi basicamente de um décimo da solução nutritiva completa.

As plântulas permaneceram nas soluçōes tratamentos durante dez dias, sem arejamento, com o $\mathrm{pH}$ das soluções mantido o mais próximo de 4,0, com ajustamentos diários.

Decorrido esse periodo, as plântulas foram retiradas das soluções tratamentos, e medido em milimetro o crescimento da raiz primária de cada uma, obtendo-se o seu comprimento. Logo após, de cada cultivar, as partes aéreas foram separadas das raízes, lavadas com água destilada 
e colocadas para secar em estufa a $45^{\circ} \mathrm{C}$ por cinco dias, sendo determinados os respectivos pesos secos. As matérias secas da parte aérea de cada tratamento foram submetidas às determinações de $\mathrm{Cu}, \mathrm{Fe}, \mathrm{Mn}$ e $\mathrm{Zn}$, segundo os métodos de BATAGLIA et alii (1).

Os dados foram analisados estatisticamente, considerando-se a média do crescimento das raízes das vinte plântulas de cada cultivar, após o cultivo em soluções de tratamento com concentrações crescentes de ferro.

\section{RESULTADOS E DISCUSSÃo}

O comprimento médio das raízes e o peso seco total da parte aérea de vinte plântulas de cada um dos cultivares de arroz, medidos após dez dias de crescimento em soluçōes nutritivas contendo diferentes niveis de ferro, encontram-se no quadro 1 e nas figuras 1 e 2 .

QUADRO 1. Comprimento médio das raízes e peso seco total da parte aérea referentes a vinte plântulas de sete cultivares de arroz medidos após dez dias de cultivo em soluções nutritivas contendo quatro diferentes concentrações de ferro

\begin{tabular}{|c|c|c|c|c|c|}
\hline \multirow[t]{2}{*}{ Cultivares } & \multirow{2}{*}{$\begin{array}{l}\text { Concentração de } \\
\text { ferro na solução }\end{array}$} & \multicolumn{2}{|c|}{$\begin{array}{c}\text { Comprimento médio } \\
\text { das raizes }\end{array}$} & \multicolumn{2}{|c|}{$\begin{array}{l}\text { Peso seco total da } \\
\text { parte aérea }\end{array}$} \\
\hline & & $\mathrm{mm}$ & $\%$ & $\mathrm{mg}$ & $\%$ \\
\hline Blue Bonnet & $\begin{array}{l}0,56 \\
100 \\
200 \\
400\end{array}$ & $\begin{array}{r}184,1 \\
107,5 \\
97,5 \\
75,0\end{array}$ & $\begin{array}{r}100 \\
58 \\
53 \\
41\end{array}$ & $\begin{array}{l}406 \\
352 \\
265 \\
229\end{array}$ & $\begin{array}{r}100 \\
87 \\
65 \\
56\end{array}$ \\
\hline Pérola & $\begin{array}{l}0,56 \\
100 \\
200 \\
400\end{array}$ & $\begin{array}{r}234,4 \\
176,5 \\
105,0 \\
71,5\end{array}$ & $\begin{array}{r}100 \\
75 \\
45 \\
31\end{array}$ & $\begin{array}{l}630 \\
582 \\
476 \\
388\end{array}$ & $\begin{array}{r}100 \\
92 \\
76 \\
62\end{array}$ \\
\hline IAC-120 & $\begin{array}{l}0,56 \\
100 \\
200 \\
400\end{array}$ & $\begin{array}{r}247,8 \\
178,0 \\
121,5 \\
83,5\end{array}$ & $\begin{array}{r}100 \\
72 \\
49 \\
34\end{array}$ & $\begin{array}{l}613 \\
448 \\
417 \\
296\end{array}$ & $\begin{array}{r}100 \\
73 \\
68 \\
48\end{array}$ \\
\hline IAC-435 & $\begin{array}{l}0,56 \\
100 \\
200 \\
400\end{array}$ & $\begin{array}{r}215,9 \\
135,0 \\
101,0 \\
67,5\end{array}$ & $\begin{array}{r}100 \\
63 \\
47 \\
31\end{array}$ & $\begin{array}{l}665 \\
460 \\
385 \\
295\end{array}$ & $\begin{array}{r}100 \\
69 \\
58 \\
44\end{array}$ \\
\hline IAC-899 & $\begin{array}{l}0,56 \\
100 \\
200 \\
400\end{array}$ & $\begin{array}{r}146,5 \\
83,5 \\
77,5 \\
67,5\end{array}$ & $\begin{array}{r}100 \\
57 \\
53 \\
46\end{array}$ & $\begin{array}{l}460 \\
369 \\
311 \\
28\end{array}$ & $\begin{array}{r}100 \\
80 \\
68 \\
62\end{array}$ \\
\hline IR-8 & $\begin{array}{l}0,56 \\
100 \\
200 \\
400\end{array}$ & $\begin{array}{r}125,6 \\
97,5 \\
72,5 \\
56,0\end{array}$ & $\begin{array}{r}100 \\
78 \\
58 \\
45\end{array}$ & $\begin{array}{l}535 \\
372 \\
327 \\
312\end{array}$ & $\begin{array}{r}100 \\
70 \\
61 \\
58\end{array}$ \\
\hline IR-841 & $\begin{array}{l}0,56 \\
100 \\
200 \\
400\end{array}$ & $\begin{array}{r}115,6 \\
68,0 \\
65,5 \\
62,5\end{array}$ & $\begin{array}{r}100 \\
59 \\
\mathbf{5 7} \\
\mathbf{5 4}\end{array}$ & $\begin{array}{l}446 \\
351 \\
316 \\
243\end{array}$ & $\begin{array}{r}100 \\
79 \\
71 \\
54\end{array}$ \\
\hline
\end{tabular}




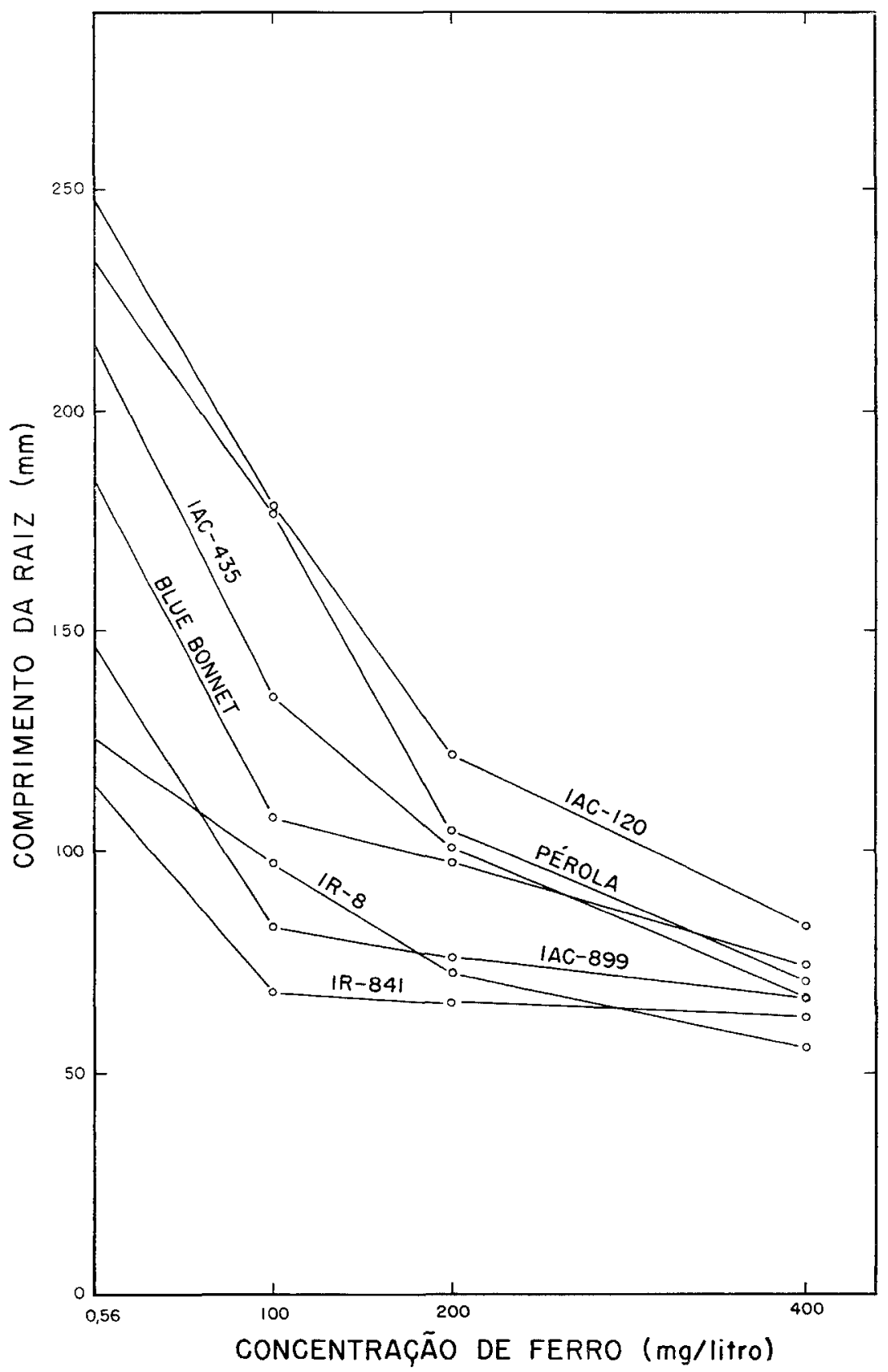

FIGURA 1. Comprimento médio das raízes de sete cultivares de arroz medidos após dez dias de cultivo em soluçōes nutritivas contendo quatro diferentes concentrações de ferro. 


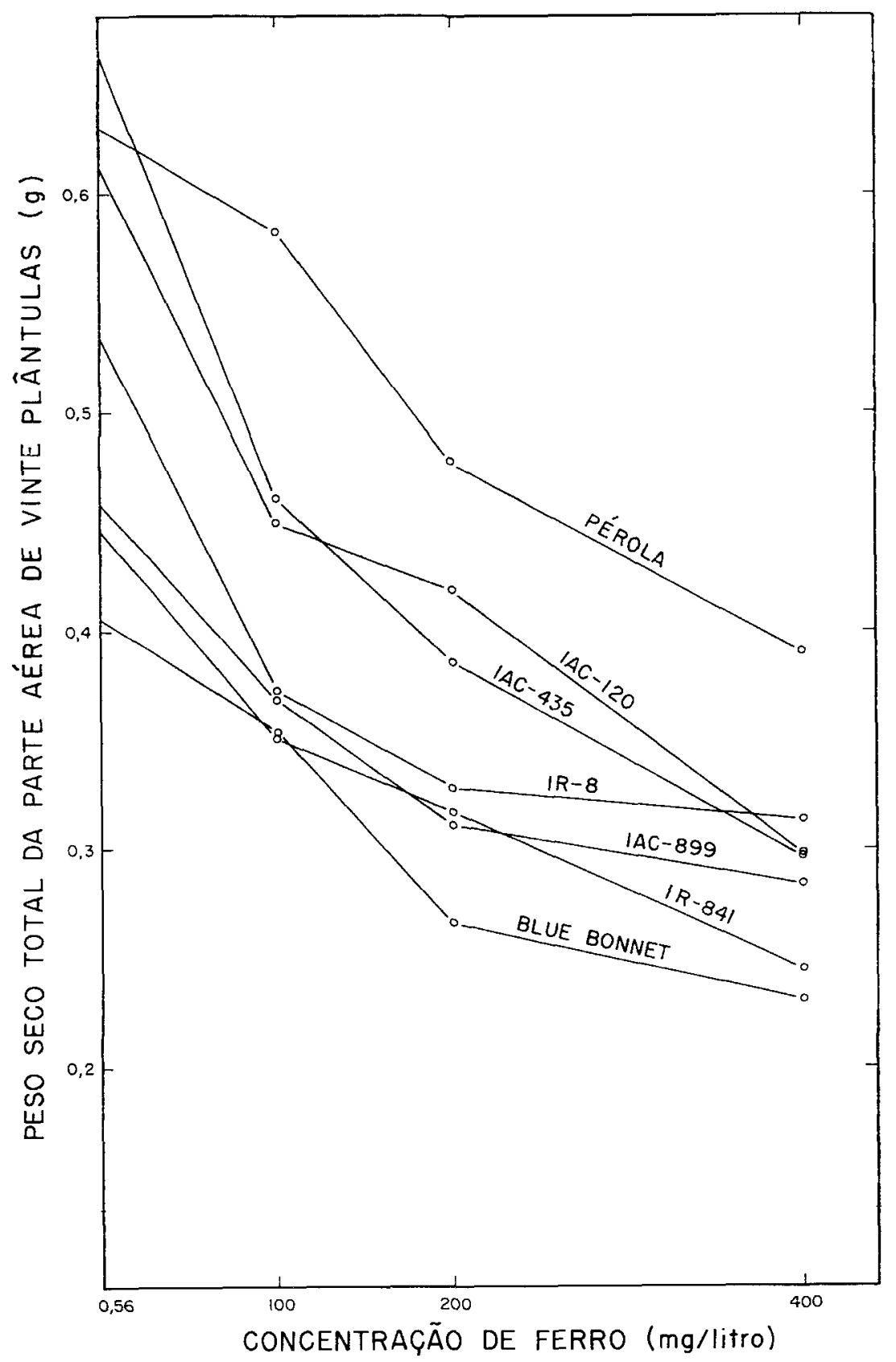

FIGURA 2. Peso seco total da parte aérea de vinte plântulas de sete cultivares de arroz medidos após dez dias de cultivo em soluçōes nutritivas contendo quatro diferentes concentrações de ferro. 
Os resultados da análise estatística desse experimento mostraram, pelo teste $F$, efeitos altamente significativos de cultivares e das concentrações de ferro nas soluções nutritivas, no comprimento das raizes e no peso seco total da parte aérea. Não foram verificadas interações significativas entre cultivares e concentrações de $\mathrm{Fe}$ nas soluções em relação aos dois parâmetros de crescimento estudados.

Com a adição das doses crescentes de ferro nas soluções, houve um efeito prejudicial em todos os cultivares estudados, que apresentaram sensivel redução no comprimento das raízes e no peso seco total da parte aérea, em relaçāo à dose de $0,56 \mathrm{mg} /$ litro de ferro, além de mostrarem com clareza os sintomas descritos na literatura por outros autores $(2,7,8,9,10)$.

Considerando o peso seco total da parte aérea, verificou-se que o cultivar Pérola foi o que apresentou maior tolerância à adição de $100 \mathrm{mg} /$ litro de $\mathrm{Fe}$ nas soluções, tendo sua produção reduzido $8 \%$ em relação à dose normal desse elemento $(0,56 \mathrm{mg} / \mathrm{litro})$. Os cultivares IAC-435 e IR-8 foram os mais sensiveis nessas condições, produzindo 31 e $30 \%$ a menos, respectivamente, em relação à dose normal. Os demais cultivares apresentaram peso seco total da parte aérea reduzido entre 13 e $27 \%$ com a aplicação de $100 \mathrm{mg} /$ litro de ferro nas soluções.

Quando foram adicionados $200 \mathrm{mg} /$ litro de ferro na solução tratamento, o cultivar Pérola se mostrou o mais tolerante, apresentando peso seco total da parte aérea reduzido de $24 \%$ em relação à dose de $0,56 \mathrm{mg} / \mathrm{li}$ tro de ferro. Os cultivares IAC-435 e IR-8 foram os mais sensíveis, mostrando peso seco da parte aérea reduzido de 42 e $39 \%$ respectivamente. Os outros cultivares tiveram sua redução variando de 29 a $35 \%$.

O cultivar Pérola, juntamente com 'IAC-899' foram os que mostraram maior tolerância a $400 \mathrm{mg} /$ litro de ferro na solução, apresentando peso seco da parte aérea reduzido de $38 \%$ em relação à concentração controle $(0,56 \mathrm{mg}$ /litro de ferro). Nessas condições, os cultivares mais sensiveis foram IAC-435 e IAC-120, com reduçōes de 56 e $52 \%$ respectivamente.

Os resultados obtidos sugeriram que, para avaliar i tolerância ao excesso de ferro nas soluções, o comprimento das raízes não se mostrou um bom parâmetro. Como justificativa, poder-se-ia considerar os cultivares Pérola e IR-8, que apresentaram peso seco da parte aérea reduzido, respectivamente, de 8 e $30 \%$ com a adição de $100 \mathrm{mg} /$ litro de ferro n: solução e tiveram, respectivamente, um crescimento menor nos seus comprimentos das raízes de 25 e $22 \%$ nas mesmas condições. Poderia ainda ser considerado que os cultivares Pérola e IAC-435 apresentaram peso seco da parte aérea reduzido de 38 e $56 \%$, respectivamente, quando foram adicionados $400 \mathrm{mg} /$ litro de ferro na solução tratamento; ambos os cultivares, porém, apresentaram crescimento médio de suas raízes reduzido de $69 \%$ nas mesmas condições. Na figura 3, acham-se ilustra- 
dos os crescimentos das raízes do cultivar IAC-435, em soluçōes nutrîtivas contendo $0,56,200$ e $400 \mathrm{mg} /$ litro de ferro.

No quadro 2, encontram-se as concentrações de $\mathrm{Cu}, \mathrm{Fe}, \mathrm{Mn}$ e $\mathrm{Zn}$ (ppm) determinadas nas partes aéreas dos sete cultivares ảe arroz desenvolvidos durante dez dias em soluçōes nutritivas contendo diferentes concentrações de ferro.

QUADRO 2. Concentrações de nutrientes na parte aérea dos sete cultivares de arroz desenvolvidos dez dias em soluções nutritivas contendo quatro diferentes concentraçōes de ferro

\begin{tabular}{|c|c|c|c|c|c|}
\hline \multirow{2}{*}{ Cultivares } & \multirow{2}{*}{$\begin{array}{l}\text { Concentração de } \\
\text { ferro nas soluções }\end{array}$} & \multicolumn{4}{|c|}{ Concentração de elementos nas folhas } \\
\hline & & $\mathrm{Cu}$ & $\mathrm{Fe}$ & $\mathrm{Mr}$ & $\mathrm{Zn}$ \\
\hline & $\mathrm{mg} /$ litro & & - & & \\
\hline \multirow[t]{4}{*}{ Blue Bonnet } & 0,56 & 35,2 & 423 & 108 & 133,2 \\
\hline & 100 & 20,5 & 1042 & 104 & 64,2 \\
\hline & 200 & 22,0 & 3250 & 100 & 69,1 \\
\hline & 400 & 16,1 & 5063 & 134 & 99,9 \\
\hline \multirow[t]{4}{*}{ Pérola } & 0,56 & 41,6 & 346 & 98 & 110,1 \\
\hline & 100 & 31,7 & 1044 & 69 & 52,3 \\
\hline & 200 & 28,0 & 1521 & 72 & 51,0 \\
\hline & 400 & 19,9 & 2559 & 82 & 57,5 \\
\hline \multirow[t]{4}{*}{ IAC-120 } & 0,56 & 44,4 & 400 & 100 & 152,0 \\
\hline & 100 & 38,3 & 1369 & 97 & 78,6 \\
\hline & 200 & 36,1 & 2457 & 102 & 73,5 \\
\hline & 400 & 31,2 & 4503 & 75 & 105,9 \\
\hline \multirow[t]{4}{*}{ IAC -435} & 0,56 & 34,7 & 356 & 102 & 95,2 \\
\hline & 100 & 33,8 & 1265 & 102 & 32,9 \\
\hline & 200 & 28,3 & 2361 & 106 & 35,2 \\
\hline & 400 & 22,6 & 3371 & 149 & 25,5 \\
\hline \multirow[t]{4}{*}{ IAC-899 } & 0,56 & 32,2 & 496 & 108 & 136,8 \\
\hline & 100 & 40,6 & 937 & 81 & 31,5 \\
\hline & 200 & 31,1 & 1968 & 136 & 34,4 \\
\hline & 400 & 30,2 & 3081 & 167 & 20,9 \\
\hline \multirow[t]{4}{*}{ IR-8 } & 0,56 & 40,3 & 403 & 114 & 91,6 \\
\hline & 100 & 34,6 & 1081 & 109 & 20,7 \\
\hline & 200 & 35,2 & 2459 & $15 \%$ & 31,8 \\
\hline & 400 & 30,3 & 2841 & 173 & 19,6 \\
\hline \multirow[t]{4}{*}{ IR-841 } & 0,56 & 30,0 & 374 & 174 & 92,1 \\
\hline & 100 & 24,0 & 966 & 106 & 47,3 \\
\hline & 200 & 29,7 & 2034 & 87 & 42,7 \\
\hline & 400 & 28,5 & 3770 & 150 & 25,2 \\
\hline
\end{tabular}




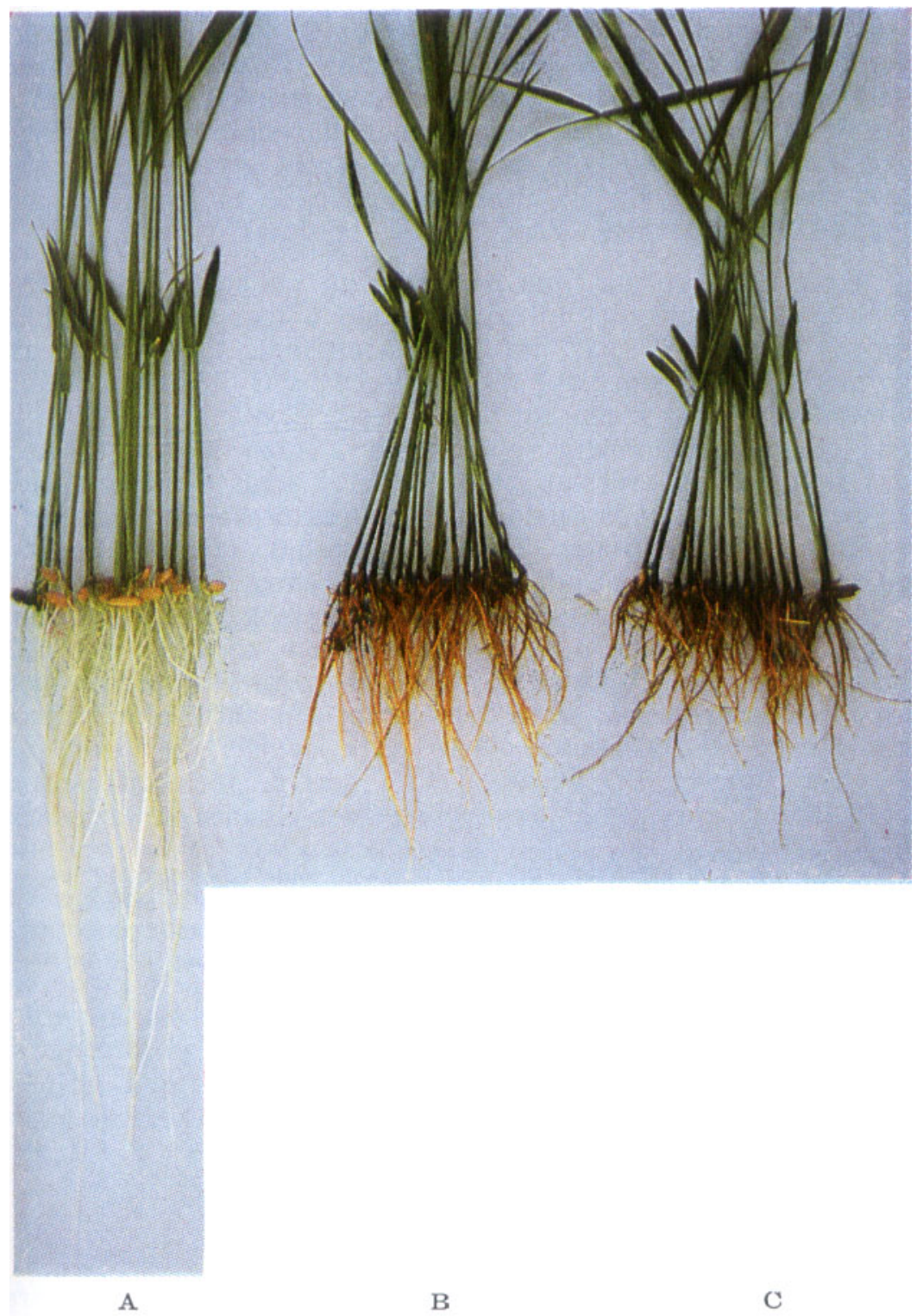

FIGURA 3. Sistema radicular de plântulas dc cultivar IAC-435 após dez dias em soluçōes nutritivas, sem arejamento, contenđo: $A$ : 0,56 , B: 200 e C: $400 \mathrm{mg} /$ itro de ferro, na temperatura de $30 \pm 1{ }^{\circ} \mathrm{C}$. 
Os teores de ferro na parte aérea dos diferentes cultivares, quando desenvolvidos em solução nutritiva com $0,56 \mathrm{mg} /$ litro de Fe, variaram de 346 a $496 \mathrm{ppm}$. TANAKA \& YOSHIDA (12) estabeleceram como limite de deficiência de ferro para o arroz $70 \mathrm{ppm}$ e para toxicidade $300 \mathrm{ppm}$, durante o período de perfilhamento. Como os resultados do presente trabalho foram com plântulas, as determinaçöes obtidas acima do limite de toxicidade não mostraram nenhum sintoma prejudicial visível às plantas estudadas, pois as plantas novas apresentam concentrações mais elevadas devido ao menor conteúdo de matéria seca diluente de elementos (carboidratos, óleos, fibras, celulose).

Os teores de ferro em ppm aumentaram na parte aérea em todos os cultivares, à medida que foi aumentando o teor desse elemento nas soluções. O cultivar Pérola, que se mostrou mais tolerante ao excesso de ferro nas soluçōes com base no peso seco total da parte aérea, foi o que apresentou menores concentrações desse elemento na parte aérea, sugerindo que sua tolerância seja devida a uma menor absorcão de ferro das soluçöes. O cultivar IAC-435 foi o mais sensivel ao excesso de ferro nas soluçōes, mostrando altos índices desse elemento na parte aérea, quando comparado com 'Pérola", sugerindo que o primeiro seria eficiente na absorção desse elemento. Por outro lado, cultivares com reaçōes intermediárias ao excesso de ferro nas soluções, tais como Blue Bonnet, IAC-120 e IR-841, e cultivares sensiveis, como IR-8 e IAC-435, apresentaram altos teores desse elemento na parte aérea, indicando que suas respostas dependem do grau de tolerância a altas concentrações de ferro no interior das plântulas e não da eficiência de absorção desse elemento das soluções. O cultivar IR-8, que se mostrou sensivel no presente trabalho, apresentou desempenho semelhante em condições de solo $(2,3,4,5)$.

As concentrações de cobre e zinco na matéria seca da parte aérea diminuíram na maioria dos cultivares, à medida que se aumentaram os teores de ferro nas soluçōes, por antagonismo catiônico.

Pelos dados obtidos, verificou-se uma tendência de aumento nas concentrações de manganês nas folhas, à medida que se aumentaram as concentraçōes de ferro nas soluções, deixando evidente que, no presente estudo, não ocorreu deficiência de manganês, e, sim, efeito tóxico de altos teores de ferro às plântulas.

\section{CONCLUSõES}

a) A técnica empregada para o estudo da reação de cultivares de arroz a crescentes concentrações de ferro, em soluções nutritivas sem arejamento; foi eficiente, possibilitando a separação de cultivares tolerantes e sensiveis em curto periodo de tempo.

b) A presença de doses elevadas de ferro como 100,200 e $400 \mathrm{mg} / \mathrm{li}-$ tro em solução nutritiva foi prejudicial a todos os cultivares estudados. 
c) O cultivar Pérola mostrou tolerância a doses crescentes de ferro nas soluções; 'IAC-435' e IR-8' foram sensiveis $\epsilon$ 'IAC-899', 'IR-841', 'IAC-120' e 'Blue Bonnet' apresentaram reações intermediárias.

d) Os teores de ferro em ppm aumentaram nas folhas de todos os cultivares em função do aumento dos teores desse elemento nas soluçōes nutritivas.

e) A maior tolerância do cultivar Pérola pareceu ser devida a uma menor absorção seletiva de ferro das soluçōes, em comparação com os outros cultivares estudados.

f) A presença de altos teores de ferro nas folhas dos cultivares com reações intermediárias e sensíveis a doses crescentes desse elemento nas soluçōes, indicou que suas respostas seriam devidas a maior ou menor tolerância a altas concentraçōes de ferro no interio: das folhas, e nāo a maior ou menor absorção desse elemento das soluções.

\section{SUMMARY}

\section{TOLERANCE OF RICE CULTIVARS IN SEEDLING STAGE TO DIFFERENT LEVELS OF IRON IN NUTRIENT SOLUTION}

Seven rice cultivars were studied to iron toxicity using four different levels of this element $(0.56 ; 100 ; 200$ and $400 \mathrm{mg} / 1)$ in nutrient solution, without aeration, under constant temperature $\left(30 \pm 1^{\circ} \mathrm{C}\right)$ and $\mathrm{pH} 4.0$. The tolerance of the plants was measured taking into account the mean of the primary root length and the total leaf dry weight of 20 seedlings per treatment solution. The presence of high levels of iron $(100 ; 200$ and $400 \mathrm{mg} / 1)$ in the solutions produced harmfull effects on all rice cultivars studied. The plants showed typical iron toxicity symptom which varied with the degree of tolerance of each cultivar. The rice cultivar Pérola was tolerant to the increasing level of iron in the nutrient solutions, IAC-435 and IR-8 were sensitive and the cultivar IAC-126, IAC-899 and Blue Bonnet were intermediate in relation to iron toxicity. The iron concentration in the leaves of all studied rice cultivars increased when the levels of iron increased in the nutrient solutions. The tolerance to iron toxicity exhibited by the cultivar Perola seemed to be associated to a lower iron uptake from the treatment solutions compared with the other cultivars under study. The presence of high iron content in the leaves of the studied cultivars showing light and severe symptoms of iron toxicity appeared to be due to a higher or lower ability of tolerating high levels of that element within its tiscues and not to a lower iron uptake.

\section{REFERENCIAS BIBLIOGRÁFICAS}

1. BATAglia, O. C.; TEIXEIRA, J. P. F.; FURLANI, P. R.; FURLANI, A. M. C.; GALLO, J. R. Métodos de análise química de plantas. Campinas, Instituto Agronômico, 1978, 31p. (Circular, 87)

2. IRON toxicity. In: ANNUAL REPORT FOR 1971. Los Baños, Philippines, The International Rice Research Institute, 1972. p.40-41.

3. - In: ANNUAL REPORT FOR 1972. Los Baños, Philippines, The International Rice Research Institute, 1973. p.197. 
4. IRON toxicity. In: ANNUAL REPORT FOR 1973. Los Baños, Philippines, The International Rice Research Institute, 1974. p.102.

5. - In: ANNUAL REPORT FOR 1979. Los Baños, Philippines, The International Rice Research Institute, 1980. p.118-119.

6. MOORE, D.P.; KRONSTAD, W.E.; METZGER, R. Screening wheat for aluminum tolerance. In: WRIGHT, Madison J., ed. Workshop on Plant Adaptation to Mineral Stress in Problem Soils, Beltsville, Maryland, 1976. Proceedings. Ithaca, Cornell University, 1976. p.287-295.

7. MOREL, D. P. \& MACHADO, M. O. Identification of iron toxicity in Brazil. International Rice Research Newsletter, 6(3):9, 1981.

8. OTA, Y. Studies on the occurrence of the physiological disease of rice called «Bronzing». Japan, National Institute of Agricultural Sciences, 1968. 104p. (Bulletin 18, Series D)

9. OU, S. H. Rice diseases. Kew, England, Commonwealth Mycological Institute, 1972. $368 \mathrm{p}$.

10. PONNAMPERUMA, F. N. Screening rice for tolerance to mineral stress. In: WRIGHT, Madison J., ed. Workshop on Plant Adaptation to Mineral Stress in Problem Soils, Beltsville, Maryland, 1976. Proceedings. Ithaca, Cornell University, 1976. p.341-353.

11. - - BRADFIELD, R.; PEECH, M. Physiological disease of rice attribut able to iron toxicity. Nature, 175:265, 1955.

12. TANAKA, A. \& YOSHIDA, S. Nutritional disorders of the rice plant in Asia. Manila, The International Rice Research Institute, 1970. 51p. (Technical Bulletin, 10)

13. VIRMANI, S. S.; TUBMAN, A. F.; SUMO, F.; WORZI, P. M. Suakoko-8 a new rice variety recommended for iron-toxic swamps in Liberia. International Rice Research Newsletter, 3(1):3-4, 1978. 